\title{
Web-enabled Information and Referral Services: A Framework for Analysis
}

\author{
Mary Helen Fagan \\ University of Texas at Tyler, Texas, USA
}

\author{
mragan@mall.uttyl.edu
}

\begin{abstract}
Information \& Referral $(I \& R)$ services help people obtain relevant and accurate information to meet specific needs. The provision of traditional $I \& R$ services by skilled specialists is being augmented by web-enabled $I \& R$ services, raising a number of issues and opportunities. First, this paper analyzes the literature on $I \& R$ services in order to understand key issues and common practices in the development of $I \& R$ services. Then a framework is presented that explores two key dimensions of $I \& R$ services: the communities of interest and communities of place that they serve. This I\&R community analysis framework is illustrated with a number of mini-case studies, and conclusions are drawn regarding how it may be applied. The findings of this study should be of interest to many organizations that want to use the web to make information readily accessible to the people they serve.
\end{abstract}

Keywords: Information \& Referral, Community of Place, Community of Interest, Community Networks

\section{Introduction}

Many organizations provide Information and Referral (I\&R) services that help people obtain relevant and accurate information to meet specific needs. Traditionally, I\&R services have been provided by a skilled specialist by phone or through a face-to-face referral process, an interaction that can depend upon good interviewing and counseling skills to succeed (Maas, 2000). A number of I\&R service providers have adopted information technology tools such as databases to facilitate the storage and retrieval of relevant I\&R resources and to help them efficiently produce printed directories. Now, many I\&R service providers see new opportunities and challenges stemming from the ability to create databases that can be accessed via the web. Like many other IT-based innovations, the adoption of web-enabled I\&R service capabilities involves a number of socio-technical issues that can affect the outcome of the process.

The goal of this paper is to provide a better understanding of the issues involved in the adoption of web-enabled I\&R services. First, this paper analyzes the literature on $I \& R$ services in order to understand key issues and common

Material published as part of this journal, either on-line or in print, is copyrighted by the publisher of Informing Science. Permission to make digital or paper copy of part or all of these works for personal or classroom use is granted without fee provided that the copies are not made or distributed for profit or commercial advantage AND that copies 1) bear this notice in full and 2) give the full citation on the first page. It is permissible to abstract these works so long as credit is given. To copy in all other cases or to republish or to post on a server or to redistribute to lists requires specific permission and payment of a fee. Contact Editor@inform.nu to request redistribution permission. practices in the development of I\&R services. Then a framework is presented that explores two key dimensions of I\&R services: the communities of place and communities of interest that they serve. This I\&R community analysis framework is illustrated with a number of mini-case studies, and conclusions are drawn regarding how it may be applied. The results of this research study should be of interest to many organizations that want to use the web to make information readily accessible to the people they serve.

\section{Literature Review}

Much of the literature on I\&R services is focused on two groups: 1) I\&R specialists in the area of health and human services and 2) librarians who provide community $I \& R$ services. A key source of information regarding I\&R for health and human services is the Alliance of Information and Referral Systems (AIRS), a non-profit organization that serves as a professional organization for over 1000 public and private information and referral providers in North America. AIRS has developed standards for professional I\&R that address key aspects of service delivery, resource databases, reporting, cooperative relationships and organizational requirements (AIRS, 2001a) and supports a practitioner oriented journal, "Information \& Referral". Guidelines for I\&R services in public libraries is provided by a number of books and articles (Bishop, et. al, 1999; Childers, 1984; Durrance and Pettigrew, 2000).

There is limited research that focuses specifically on the provision of web-enabled I\&R services. Most of the literature consists of case studies that report successful attempts to provide I\&R service online (Merrill, 1992; Van Camp, 
1990). One document that takes a larger view of the issue is the AIRS position paper on the role of I\&R in the national information infrastructure. The report found that "political and legislative decision makers are largely unaware of the role we [I\&R professionals] play in the information arena and continue to draft proposals that duplicate our efforts and assign to others responsibilities that we are better equipped to handle" (AIRS, 2001b). The report takes the position that the professional I\&R providers represented by AIRS should play a key role in determining how $I \& R$ services are provided on the information superhighway and identifies a number of issues that should be addressed. The position of I\&R providers regarding web-enabled I\&R services can be summed up by this statement from the AIRS' Standards for Professional Information and Referral manual: "Under no circumstances shall technology reduce or replace supported access through a qualified I\&R specialist. The main role of technology is to enhance or strengthen person-to-person contact, not to reduce or eliminate such contact or to make it more difficult" (AIRS, 2000, p. 15, italics added). I\&R specialists also serve a critical role in evaluating information and determining how entries should be classified in online I\&R databases (INFO LINE of Los Angeles, 1974).

Research has also explored how public libraries can effectively provide community information via the web. The most comprehensive study was performed by Project CIRCE, an eighteen month research project that explored the feasibility of creating a distributed community information network among British libraries (Leech, 1999). This research explored key issues such as 1) the relationships between the library sector and external organizations, 2) the role, aims, and content of a future community information network, 3) social and technical issues associated with the creation of a community information network, and 4) the need for information retrieval standards. A key conclusion of this 187 page report was that there are "unprecedented opportunities arising for creating new networked resources" and that it is "important that libraries seize the opportunity to create these resources, and in doing so retain their role as major players in the provision of networked community information" (Leech, 1999, italics added).

Both categories of traditional I\&R providers express concerns that others who are working to define and build community information resources may usurp their traditional role and that their unique skills and perspectives may be overlooked. For example, many cities and counties are working to build Community Networks $(\mathrm{CN})$ that allow citizens access to a wide range of information resources (Schuler, 1996). These community networks may duplicate health and human service information that has been maintained by traditional I\&R providers. Researchers have explored the differences between $I \& R$ agencies and community networks and found that organizational roles and control issues need to be examined in order to deal with information ownership and quality concerns (Pettigrew \& Wilkinson, 1996). Case studies have been used to help encourage libraries to enhance the role they play in the provision of community information via the Internet (Durrance \& Pettigrew, 2000).

A better understanding of how I\&R services can be provided via the web and how this effort relates to emerging community networks will require the use of appropriate conceptual research models and findings from a variety of domains (Bishop, et al., 1999). One design principle of successful communities indicates "group boundaries must be clearly defined so that there is a clear sense of who is making use of collective resources" (Kollack, 1998). The emerging literature on online community networks has identified two key dimensions that can be used to compare and contrast various I\&R efforts: the communities of interest and communities of place that they serve (Horan, 2000). By clarifying the communities of interest served by a web-enabled I\&R system, information providers can more readily identify the scope of the needed content, and, in addition, who might own and maintain it. Communities of interest that are not bounded by any specific geographic space are often termed virtual communities. However, more research is indicating that it is important to link information resources to their territorial or geographic place, whenever possible, in order to increase its usefulness. By clarifying the communities of place served by a webenabled I\&R system, locality can become an important attribute of an information resource and assist with searching and enhanced information provision (e.g., via maps).

\section{A Framework for Analysis}

The following I\&R community analysis framework (Figure 1) has been developed to help compare and contrast I\&R efforts. The communities of place that an I\&R service may serve can consist of a large geographic area, as in the

\begin{tabular}{|c|c|c|c|}
\hline \multirow[t]{3}{*}{$\begin{array}{l}\text { Communities } \\
\text { of Place } \\
\text { (Geographic } \\
\text { Scope) }\end{array}$} & \multirow[t]{3}{*}{$\begin{array}{l}\text { Multi- } \\
\text { ple/Large } \\
\uparrow \\
\downarrow \\
\text { Few/ } \\
\text { Small }\end{array}$} & $\begin{array}{l}\text { Children } \\
\text { in Crisis } \\
\text { Non-Profit } \\
\text { (Nationwide) } \\
\\
\text { United Way } \\
\text { INFOLINE } \\
\text { (Regionwide) }\end{array}$ & $\begin{array}{l}\text { Maryland } \\
\text { Share } \\
\text { (Statewide) } \\
\text { Community } \\
\text { Network } \\
\text { (Citywide) }\end{array}$ \\
\hline & & \multicolumn{2}{|c|}{ Narrow $\leftarrow \rightarrow$ Broad } \\
\hline & & \multicolumn{2}{|c|}{$\begin{array}{c}\text { Communities of Inter- } \\
\text { est } \\
\text { (Content scope })\end{array}$} \\
\hline
\end{tabular}

Figure 1: I\&R Community Analysis Framework 
case of a national clearinghouse, or be limited to a specific state, region or city. The communities of interest that an I\&R service may serve can be relatively narrow (e.g., disability related resources) or relatively broad (community health resources). This study uses four mini-case studies with which the author was involved to illustrate these two dimensions of the framework.

\section{Scenario \#1 - Children in Crisis Non-Profit}

\section{Description}

The Children in Crisis Non-Profit (CICNP) is a relatively new organization that works to provide information to help children in crisis and those who care for them. CICNP receives phone calls from across the nation when individuals (such as family members and professionals) need assistance with problems such as where to place an adolescent who needs mental health treatment. The CICNP director and board believed that a web-enabled database could be a very effective tool to help them fulfill their mission. However, after some analysis, the CICNP director determined that existing software products designed for I\&R applications would not fit their unique requirements. Unfortunately, CICNP was unable to outsource the development of a customized database and web-enabled I\&R system that might cost many thousands of dollars to implement. The CICNP made use of pro-bono donations of time and expertise from local IT vendors and university faculty to help them develop their data model and prototype their web site interface while they worked to identify a source of funding that would allow them to build their desired web-enabled I\&R service.

\section{Issues}

CICNP was able to focus or narrow the community of interest they served to children who were in crisis. CICNP had a core set of information resources related to the problems of juveniles (children who were involved with the criminal justice system), and, in particular, juveniles needing mental health evaluation and/or treatment. However, they wanted the database design to be flexible enough to include information related to any other type of crisis that might arise and for which they could be contacted for help. The desire to provide flexibility for expansion made it 1) challenging to finalize their data requirements and determine if a packaged solution would suffice and 2) difficult to distinguish how their information resources would differ from other national clearinghouses that focused on specific issues relating to children. CICNP also wanted to serve clients nationwide, but they realized it would be very challenging to maintain accurate and detailed information relevant to a large number of geographic areas or communities of place. CICNP developed a strategy that involved creating affiliate groups in various cities who would identify local resources for placement in the CICNP database.
The number and focus of these local affiliate groups would, in practice, determine what communities of place and interest that the CICNP could effectively serve.

\section{Scenario \#2 - Maryland SHARE}

\section{Description}

Libraries have traditionally provided broad-based community information for their patrons. Maryland has been an innovator in using libraries to provide a variety of information resources to the public, and their vision has become a reality with the implementation of Sailor, the Maryland Public Information Network (Davis, 1996). One aspect of Sailor is Maryland Share, an online portal that links together a number of community information databases that were developed independently by county libraries (14tp:164.26.76.132:10084h. For example, in Salisbury Maryland, the Wicomico County Library reference librarian developed and maintained a manual "community information file" describing local organizations and the services they provided. This information file allowed the Wicomico County librarian to answer questions ranging from "where can I get food aid" to "is there a local group interested in growing orchids". Eventually, a federal grant enabled the Wicomico County Library to join with the libraries in Worcester and Somerset counties to build "Your Community Link", a tri-county community information resource that can be accessed via Maryland Share portal or directly on the web (http://heron.Wico.11b.md.us:817).

\section{Issues}

The county libraries that participate in Maryland Share differ in what communities of interest they choose to serve. Libraries can choose to provide information on social service agencies, separate information on the programs offered by larger agencies, information on local clubs, and/or information on local events. "Your Community Link" decided to gather and maintain a wide range of information resources to serve many communities of interest. The Library of Congress MARC Community Information File format allows this non-bibliographic information to be cataloged and accessed by a variety of library automation programs. Ideally, the community information resources contained in the various library databases networked through Maryland Share could be searched in a flexible manner to provide information related to a variety of geographic locales or communities of place. However, the fact that different libraries used different software programs to build their databases means that some counties could not be accessed via Maryland Share, and other counties could not be included in a multiple county search function (an important feature since a relevant resource may be located nearby, but in a different county). The Maryland Share system allows each county to determine 
the communities of interest for which they are willing to gather and maintain relevant information resources, and the Maryland Share portal enables these information resources to be combined across communities of place.

\section{Scenario \#3 - United Way INFOLINE}

\section{Description}

Some of the issues that affect local organizations who provide access to community information resources can be illustrated by the example of a United Way INFOLINE (UWI) located in Texas. The UWI I\&R service is staffed by a number of trained volunteers who can effectively evaluate the needs of diverse callers and direct them to the appropriate community-based or government agencies. The UWI required a specialized software system to catalog their many community resources and to facilitate searching, and so they purchased the IRis software product (nttp://www.suncoastprograms.com. The UWI generated web pages from their IRis database so that users can access I\&R information on the web. The web page for each program provides a link to the organization's web site, if available.

\section{Issues}

The UWI provides information for a relatively narrow community of interest since they only maintain information in their database related to health and human services available in the city and county where they are located. The UWI has had to make a number of decisions about the communities of interest they will serve on an ongoing basis. For example, the UWI used to provide some information on local clubs and organizations via their online database, but decided to simplify maintenance and now just refers callers to the club directory that is published annually by the local paper. Currently the UWI is re-examining how they serve particular communities of interest as they consider how they might work with a Center for Independent Living (CIL) that was recently created in their city with a federal grant. The CIL is required to provide I\&R services to people who need assistance to continue living independently (such as people with disabilities and the elderly). If the UWI can enlarge the scope of their content to encompass all the resources that might be identified by the CIL, then the CIL might be able to utilize the UWI database and web interface. If the two organizations cannot find a way to collaborate, then they will be storing and maintaining some overlapping information resources. In terms of the communities of place it serves, the UWI has been focused on providing I\&R resources to a relatively small geographic area. However, the UWI was selected to be one of the 25 area information centers that will support 211 implementation in the state of Texas (TIRN, 2001) and so it is figuring out how they can expand the communities of place they serve from one to thirteen counties. The UWI has to continually address questions about what content scope they should maintain in order to serve their communities of interest and how they can extend their geographic reach to effectively serve multiple communities of place.

\section{Scenario \#4 - Metropolitan Community Network}

\section{Description}

A metropolitan area received a grant from a state agency to help them develop a community network. Representatives from city government, the city library, local schools, hospitals, non-profits and businesses formed a committee and elected a board of directors to implement their proposal and oversee the administration of the grant funds. When a prototype of the community network web site was developed, questions arose regarding what communities of interest the network should serve and the subsequent content that it should therefore provide. For example, the community network prototype included links to local businesses with an online presence. The question arose: "should our community network have links to businesses or just to non-profit programs?" Until the community network organizers determined what communities of interest they intended to serve (e.g., users who wanted to find the web address for a local business?), they could not easily decide what content/links that they should maintain.

\section{Issues}

At this point in time it is unclear if and how the community network will provide information on local businesses. However, the consensus seems to be that a number of enterprises are providing links to businesses, whereas complete information on local health and human service programs and other public information resources is not so readily available. Therefore the community network is looking at using some of its funding to purchase a webenabled I\&R software package that can be populated with data from the local United Way I\&R database and then expanded to include a wider range of information resources that the United Way does not care to collect and maintain (e.g., local clubs and organizations). Eventually, the community network intends to serve the metropolitan area that extends beyond the city where most of the organizers live. However, at this point in time, little analysis has been done on the different communities of place that this network could support, and how their information needs might differ. For this community network effort, the question of what links should be included was directly related to the perception of what communities the network wanted to serve, and in what way. 


\section{Discussion and Conclusions}

The I\&R community analysis framework suggests that one fruitful way to compare and contrast various I\&R efforts is in terms of the communities of interest and communities of place that they serve. If a non-profit (such as CICNP) does not develop a clear vision of the communities of interest they will serve and determine how they can gather and maintain accurate and relevant information for many widely scattered communities of place, they will probably face significant challenges in establishing their webenabled I\&R service. The experience of Maryland Share illustrates how a statewide portal can provide access to independently maintained county level community information databases that serve diverse communities of interest. The United Way INFOLINE experience illustrates the challenges faced by many I\&R providers when they must evaluate the pros and cons of collaborating with another organization when the communities they serve overlap (e.g., with the new Center for Independent Living). Finally, the experience of the Metropolitan Community Network effort reflects the complex future environment that faces traditional I\&R providers. In this environment, a local library may provide access to a local community network, and, at the same time, see itself in competition with the community network as an information provider (Schamber \& Sullivan, 1999).

In order to effectively provide web-enabled I\&R services, providers must address a number of social issues (e.g., if/how to collaborate) as well as technical concerns (e.g., data compatibility and the infrastructure for data sharing and transfer). Current developments such as the provision of a nationwide 211 service for community information \& referral (similar to 911) can be expected to further exacerbate these challenges (Pelletier, 2001). This study indicates that a consideration of I\&R services in terms of the communities of interest and place that they serve can provide a useful starting point for analysis.

\section{References}

AIRS. (2001a). Alliance of Information and Referral Systems Standards for Professional Information and Referral. Accessed October 1, 2001 at http://airs.org/standard 1.htm

AIRS. (2001b). Alliance of Information and Referral Systems - The Role of Information and Referral in the National Information Infrastructure: An AIRS Position Paper. Accessed October 1, 2001 at http://WwW.airs.org/library/airsposition.htm

AIRS. (2000). Standards for Professional Information and Referral, $4^{\text {th }}$ ed. Seattle: Alliance of Information and Referral Systems.

Bishop, A. P., Tidline, T., Schoemaker, S. \& Salela, P. (1999). Community Networking Initiative Research and Evaluation Activities: Methodological Issues Relating to Evaluating Users Needs and Outcomes Related to Community Information Sys- tems, Evaluating and Using Networked Information Resources and Services. In: ASIS Mid Year Meeting Proceedings. Pasadena, California, May 24-26, 1999.

Bruns, P. (1992). The USMARC Community Information Format: A History and Brief Description. Information Technology and Libraries, 11(4), 373-403.

Childers, T. (1984). Information and Referral: Public Libraries. New York: Ablex.

Davis, D. M. (1996). Designing a Collective Development Plan for Sailor, Internet Research: Electronic Networking Applications and Policy, 6(4), 48-52.

Durrance, J. C. \& Pettigrew, K. E. (2000). Community Information: The Technological Touch. Library Journal, 125 (2).

Horan, T. A. (2000). A New Civic Architecture: Bringing Electronic Space to Public Place. Journal of Urban Technology, 7(2), 5983.

INFO LINE of Los Angeles. (1974). A Taxonomy of Human Services: A Conceptual Framework with Standardized Terminology and Definitions for the Field, Los Angeles: INFOLINE of Los Angeles and Alliance of Information and Referral Systems.

Kollock, P. (1998). Design Principles for Online Communities. Accessed October 12001 at http://www.sscnet.ucla.edu/soc/faculty/kollock/papers/design.h $\underline{\operatorname{tm}}^{\mathbf{0}}$

Leech, H. (1999). CIRCE: Better Communities through Better Information. Library and Information Commission Research Report 1 . The Library and Information Commission. Accessed October 1, 2001 at http://Www.gloscc.gov.uk/circe/

Maas, N. L. (2000). The Information \& Referral Interview: Models to Remember. Alliance of Information and Referral Systems. Accessed October 1, 2001 at hitp://airs.org/library/Foundations.PDF

Merrill, F. (1992). Automating the Information and Referral Function at a Regional Senior Citizens Center. Journal of Systems Management, 43(10), 6-9.

Pelletier, E. (2001). 211 State by State: Nationwide Implementation of 211-Accessed Information and Referral Services. Telecommunications and Policy Institute, University of Texas at Austin, Accessed October 1, 2001 at hitp://www.utexas.edu/research/tipi

Pettigrew, K. E. \& Wilkinson, M. A. (1996). Control of Community Information: An Analysis of Roles. Library Quarterly, 66(4), 373-408.

Schamber, L. \& Sullivan, T. (1999). Winners and Survivors: Evolution of Digital Community Networks, Evaluating and Using Networked Information Resources and Services, In: ASIS Mid Year Meeting Proceedings. Pasadena, California, May 24-26, 1999. 
Schuler, D. (1996). New Community Networks: Wired for Change. Addison Wesley Publishing. Accessed October 1, 2001 at nttp://www.scn.org/ncn/

TIRN. (2001). Texas I\&R Network - Area Information Centers. Accessed October 1, 2001 at nttp://www.hnsc.state.IX.us/tirn/aictist.htm

Van Camp, A. (1990). DIRLINE: An Online Directory of Health Information and Resources. Online, 14(6): 109-111.

\section{Biography}

Dr. Fagan is an assistant professor of Information Systems in the College of Business and Technology at the University of Texas at Tyler. Prior to joining academia, she worked as a manager for a global IS consulting firm, gaining diverse industry and technical experience. Dr. Fagan's research focuses on the factors that influence the adoption and diffusion of IT innovations and on emerging applications such as community information systems. 